\section{Esophageal vascular ectasia}

A 76-year-old man presented with symptomatic anemia and a hemoglobin of $6.5 \mathrm{~g} / \mathrm{dL}$. His medical history included aortic valve replacement requiring chronic anticoagulation, Barrett's esophagus, and gastric antral vascular ectasia (GAVE) previously treated with argon plasma coagulation (APC). After transfusion and reversal of anticoagulation, an esophagogastroduodenoscopy was performed, confirming the presence of Barrett's esophagus. There was a broad area of friable vascular ectasia extending up the Barrett's segment from the gastroesophageal junction, with an additional small ectasia at the squamocolumnar junction ( $\bullet$ Fig. 1 a,b). The broad tongue of ectasia within the Barrett's segment was lifted with submucosal injection of dilute hydroxypropylmethylcellulose, and the esophageal ectasia were treated with APC ( $\nabla$ Fig. 1 c). The patient returned for follow-up endoscopy 9 months later. There were several remaining esophageal vascular ectasia (EVE) ( $\bullet$ Fig. 2) and these were treated with cryotherapy.
We have described the emergence of EVE in a patient with a history of Barrett's esophagus, who had previously been treated for GAVE. GAVE is an uncommon cause of upper gastrointestinal bleeding and is associated with cirrhosis, portal hypertension, or chronic renal failure $[1,2]$. EVE has been previously described in a patient with Fabry's disease [3]. While ectasia of the gastric cardia often occur in patients with GAVE, ectasia in Barrett's esophagus have not been previously described. We chose to treat EVE endoscopically with methods previously used for treatment of GAVE [4,5], however, caution must be taken to minimize the risk of esophageal perforation.

\section{Endoscopy_UCTN_Code_CCL_1AB_2AC_3AG}

\section{Competing interests: None}

\section{S. Khanna, A. S. Arora, M. D. Topazian} Division of Gastroenterology and Hepatology, Mayo Clinic College of Medicine, Rochester, Minnesota, USA

\section{References}

1 Foutch PG. Angiodysplasia of the gastrointestinal tract. Am J Gastroenterol 1993; 88: 807-818

2 Regula J, Wronska E, Pachlewski J. Vascular lesions of the gastrointestinal tract. Best Pract Res 2008; 22: 313-328

3 Okano H, Shiraki K, Tsuneoka Ket al. Esophageal vascular ectasia associated with Fabry's disease. Gastrointest Endosc 2001; 53: 125 126

4 Rosenfeld G, Enns R. Argon photocoagulation in the treatment of gastric antral vascular ectasia and radiation proctitis. Can J Gastroenterol 2009; 23: $801-804$

5 Feitoza $A B$, Gostout CJ, Burgart LJ et al. Hydroxypropyl methylcellulose: A better submucosal fluid cushion for endoscopic mucosal resection. Gastrointest Endosc 2003; 57: $41-47$

\section{Bibliography}

DOI $10.1055 / \mathrm{s}-0030-1256427$

Endoscopy 2011; 43: E281

(c) Georg Thieme Verlag KG Stuttgart · New York ISSN 0013-726X

\section{Corresponding author \\ M. D. Topazian}

Division of Gastroenterology and Hepatology

Mayo Clinic College of Medicine

200 First Street SW

Rochester

MN 55905

USA

topazian.mark@mayo.edu

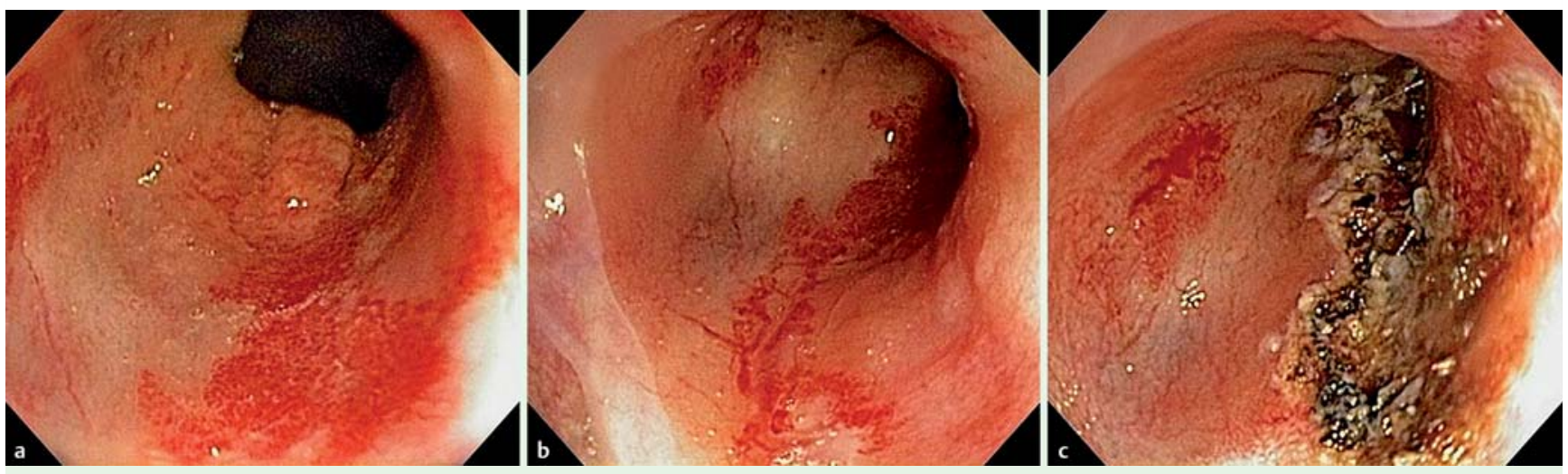

Fig. 1 a-c Esophageal vascular ectasia (EVE) within Barrett's esophagus, treated with argon plasma coagulation (APC).
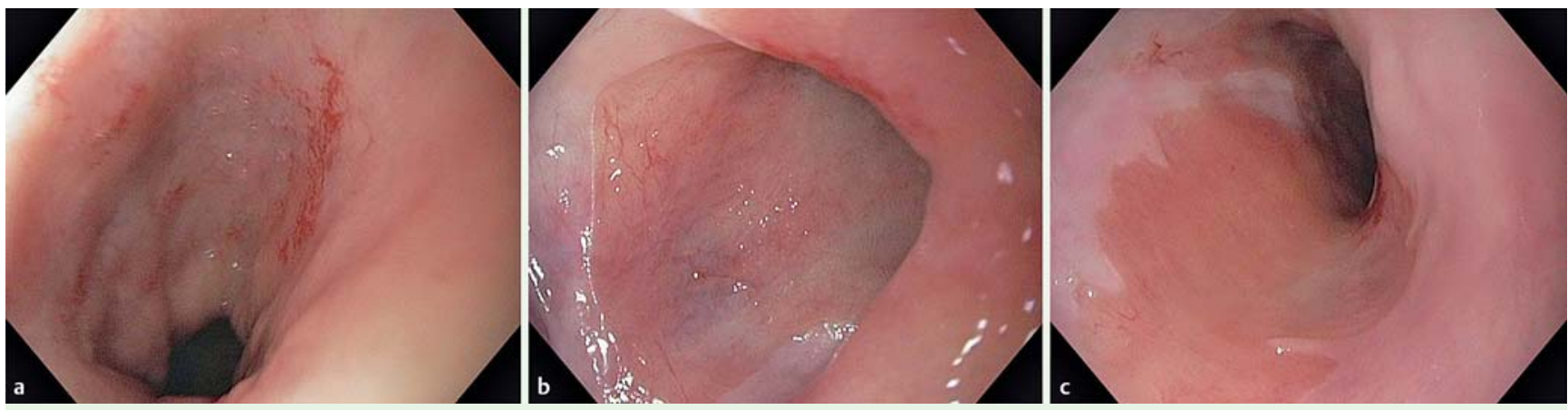

Fig. 2 Residual vascular ectasia in the esophagus at a follow-up endoscopy at 9 months. 